\title{
A Survey Of Knowledge Management Skills Acquisition In An Online Team-Based Distributed Computing Course
}

Jennifer D. E. Thomas, (E-mail: jthomas@pace.edu), Pace University

\begin{abstract}
This paper investigates students' perceptions of their acquisition of knowledge management skills, namely thinking and team-building skills, resulting from the integration of various resources and technologies into an entirely team-based, online upper level distributed computing (DC) information systems (IS) course. Results seem to indicate that more support of the thinking skills was provided by the offline resources than by the online resources, while both the online and offline resources were perceived as providing a lot of support for the team-building skills.
\end{abstract}

Keywords: knowledge management skills, online learning, thinking skills, team-building skills.

\section{INTRODUCTION}

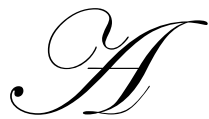

s academics, our overarching aim should be to imbue in our students problem-solving skills, research skills, critical thinking, and creative idea generation, along with various team-building skills, with a view to fostering life-long learning which will be transferable to the organizational setting. The development of these knowledge management skills is supported and facilitated by the resources, activities and technologies integrated into course design and delivery (Thomas, 2005).

A previous paper explored students' perceptions of the acquisition of these knowledge management skills in web-assisted upper level distributed computing courses, as a consequence of various resources, activities and technologies (Thomas, 2005). In that study, it was found that offline resources were perceived as giving strong support to higher-order thinking and team-based skills but that online resources provided only moderate support. As a consequence of those results, in this paper, the attention is focused on an entirely team-based online course. As organizations become more global, the possibility of working entirely in virtual, distributed environments increases. The team-based, online course delivery format simulates these conditions.

Users' perceptions of the supporting technologies and the delivery of material in this context are important considerations, both in academia and in industry, as system use has been found to be related to user's perceptions (Davis, 1989). Hence, this paper explores students' perceptions of resources, assignments and activities and their contribution to their learning, as they engage in an entirely online Distributed Computing course.

\section{BACKGROUND}

Knowledge management can be defined as, "a methodology for systematically gathering, organizing, and disseminating information. It essentially consists of processes and tools that effectively capture, store and share data”. (Gabberty \& Thomas, 2007; Sambamurthy \& Subranani, 2005; Hult, 2003; Nonaka, 1991). Nowhere more than in the learning environment are these notions pertinent.

Transfer of knowledge, be it tacit or explicit, requires that there be sources of knowledge and mechanisms for facilitating transfer of this knowledge, which include mentors, training, labs for testing and practicing the learning and occasions for reflection on the learning. It requires access to on- and offline resources such as notes, texts, 
assignments, tests, projects, Internet resources, etc. There has to be a means of organizing, articulating and sharing the learning which would involve email as well as offline exchanges, idea organizers, discussion facilities, brainstorming tools, etc. And of course, means for storing this acquired knowledge is required. (King, 2006)

Figure 1 identifies a number of tools, techniques and resources to support the knowledge management function. These are based on Nonaka's (1991) SECI (Socialization/ Externalization/ Combination/ Internalization) knowledge creation model. The successful transfer of course content and higher-order skills, such as thinking and team-building skills, requires support from these various on- and offline resources, whether in an organizational setting or in academia. When this transfer is attempted in an entirely online context, the challenge is greater, as compensation has to be made for those offline resources and activities, which may not be transplantable to the online environment.

Figure 1 - Knowledge Management Resources and Academic Application

\begin{tabular}{l|l|l}
\hline $\begin{array}{l}\text { Knowledge } \\
\text { Creation }\end{array}$ & Knowledge Management Resources & Academic Application \\
\hline Tacit to Tacit & Training, mentoring & Training, mentoring, labs, reflection \\
$\begin{array}{l}\text { Explicit to } \\
\text { Tacit }\end{array}$ & $\begin{array}{l}\text { Intranets, decision support tools, data mining, web } \\
\text { portals, data warehouses, groupware, bulletin boards, } \\
\text { information retrieval systems, videoconferencing }\end{array}$ & $\begin{array}{l}\text { Internet, texts, on- \& offline course notes, } \\
\text { assignments, tests, projects, on- \& offline discussions, } \\
\text { groupware videoconferencing, }\end{array}$ \\
$\begin{array}{l}\text { Tacit to } \\
\text { Explicit }\end{array}$ & $\begin{array}{l}\text { Work flow systems, web mapping, content mapping, } \\
\text { knowledge mapping, knowledge networks, } \\
\text { brainstorming, mentoring, retreats, training }\end{array}$ & $\begin{array}{l}\text { Mentoring, on- \& offline training, on- \& offline } \\
\text { discussion, reflection, assignments, papers, projects, } \\
\text { exams, brainstorming, idea organizer }\end{array}$ \\
$\begin{array}{l}\text { Explicit to } \\
\text { Explicit }\end{array}$ & Repositories of successes, failures and lessons learned & On- \& offline repositories \\
\hline
\end{tabular}

Adapted from: Nonaka, 1991; Bayraktaroglu \& Koutanis, 2003; Liebowitz, 2002; Torrellas, 2002; Speter \& Speter, 2003 (See Thomas, 2005)

The efficacy of online learning is by no means straightforward. Understanding learning itself without the additional interjection of technology into the mix is a daunting task given the complexity and number of dimensions that need to be considered.

Ein-Dor identified 5 main and 3 sub-dimensions of knowledge, which can be arrayed along various spectra. (Figure 2).

Figure 2 - Dimensions of Knowledge

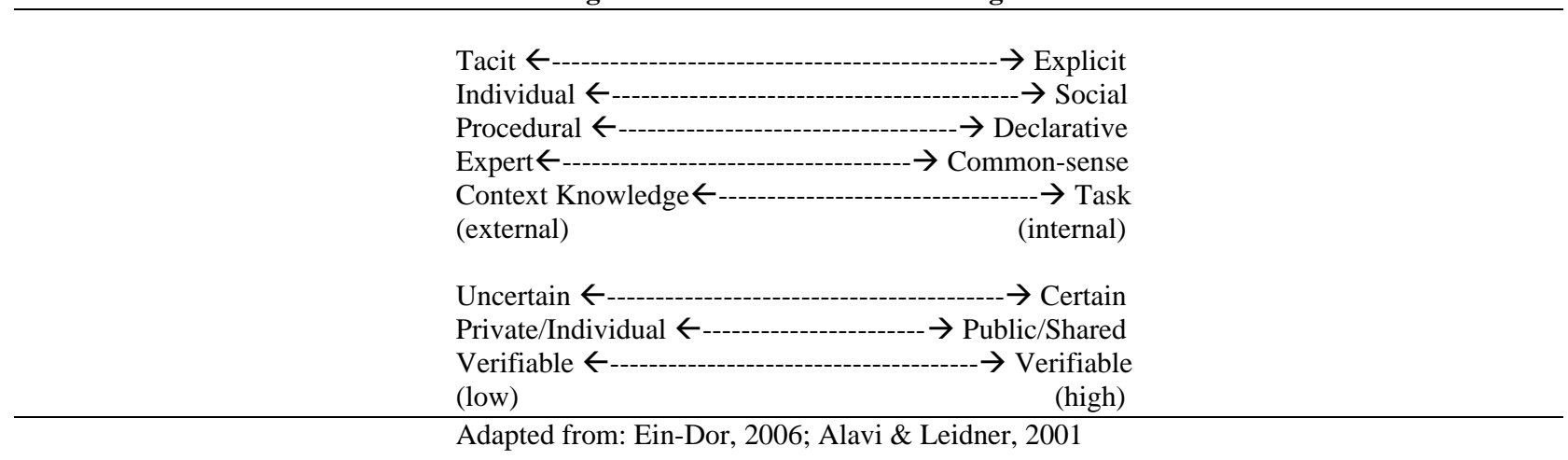


On the right of the spectra, knowledge is seen to be explicit or easily articulated, therefore more readily available for social or public sharing. This knowledge is often in the realm of declarative knowledge and commonsense knowledge and easily represented in well- defined tasks, or steps - the know what. This knowledge is usually certain and easily verifiable and measurable.

On the other end of the spectrum, knowledge can be seen as tacit or difficult to articulate, the purview of the expert, making this knowledge more the property of the individual and private. This knowledge would be contextual and include understanding of procedural knowledge - the know how. The Alavi and Leidner (2001) model integrates causal knowledge - the know why. This knowledge is harder to measure and verify for authenticity. In any learning setting, the possible combination of these dimensions is astronomical. Add technology to the mix and the task is almost overwhelming.

According to Heavin and Neville (2006) concerning the Reeves and Reeves (1997) model, ten dimensions for interactive training and collaboration should be considered. (Figure 3).

Figure 3 - Dimensions of Interactive Training and Collaboration

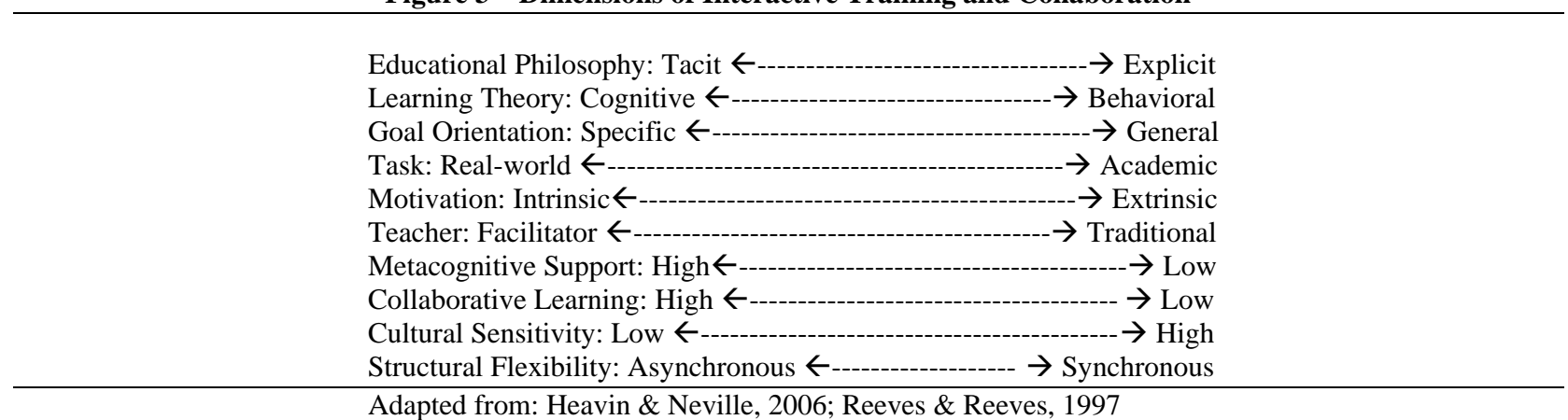

Adapted from: Heavin \& Neville, 2006; Reeves \& Reeves, 1997

On the right of the spectrum, adopting a behavioral learning theory strategy, the goals are more easily specified and the tasks are usually academically oriented. Motivation is usually extrinsically applied and the teacher's role that of the traditional, lecturer. Collaboration is usually low and learning follows a synchronous model. Adaptation to cultural sensitivity is more readily addressed given the immediacy of the environment. Metacognitive support tends to be low.

On the other hand, when the learning theory approach adopted is cognitive, more general goal orientation is possible, tasks are more real-world and intrinsic motivation is required as the teacher role becomes one of facilitator. Metacognitive support is high and collaborative learning plays a higher role. Learning can take place in either a synchronous or asynchronous environment, with cultural sensitivity harder to achieve in the asynchronous environment where immediacy is lost.

In situating research within the spectra of these models, future comparison across studies is facilitated and ameliorated (Thomas \& London, 1997). In this study by adopting a team-based, discovery learning strategy, students are being asked to acquire the entire spectrum of each of the dimensions of knowledge proposed by Ein-Dor (2006), as they operate at the individual, within team, and across team levels. It also pre-supposes a learning theory strategy closer to the cognitive end of that spectrum with focus on specific goals defined by the individual cases, which are real-world oriented.

As the learning environment is online, intrinsic motivation would need to be high, as the instructor adopts more of a role of facilitator in the learning process. The onus for collaboration is high, given the team-based, discovery learning approach and the asynchronous environment mode. This approach should also be conducive to support of metacognition. It is hard to say anything concerning addressing the cultural sensitivity of an online 
environment with students coming from varied cultural backgrounds and online computer experience, and given that enrollment is voluntary. However, in the asynchronous environment, quick adaptation to issues which may arise is likely to be a challenge.

It is within this complex context then that this study surveys students' perceptions of the knowledge management skills they are acquiring through the supports and resources provided.

\section{THE STUDY}

The study sought to determine the extent to which students' perceived their acquisition of various thinking and team-building knowledge management skills were supported by various resources and activities in an entirely team-based online course. The resources included the textbook, access to course management software content and features, which included material provided by the textbook author in PowerPoint slides. Students also made use of personal productivity software, Word, PowerPoint and Visio, and the Internet. Activities and assignments involved the solving of real-world case studies, written presentations of these analyses which were posted to a public discussion forum for access by all teams, critiquing of other teams' proposals, rebuttal of critiques, and participation in other general online discussion forums.

The course in question was an upper level Distributed Computing course in Information Systems. This online course was taught using a case-based, team-based, discovery-learning approach. Students worked in virtual teams, assigned by the instructor, to solve several realistic cases during the term, revolving around the same company. Cases involved students deriving recommendations about the features and technologies needed to address various aspects of the distributed computing needs of the organization. This was done within the business objectives and current infrastructure parameters of the firm.

The teams were supported by facilities available in the course management system, Blackboard, for storage of files, access to private in-team and public discussion boards, online chat, individual and team email and file exchange. These are all resources identified in the knowledge management literature as pertinent in organizations, especially distributed working environments.

\section{METHODOLOGY}

Students were asked to indicate the level of support they perceive, A lot (L), Somewhat (S), Not at all (N), for the thinking skills, identified as creative idea generation, problem-solving, critical thinking, conducting research, and the team-building skills, identified as communication skills, team cooperation, work coordination. This they indicated for the textbook used in the course, the cases analyzed, the team activities, the material on Blackboard, Blackboard overall, and the public and in-team discussion board forums.

The author developed this survey. It was felt that a three-scale instrument would adequately capture the distinction between the students' perceptions, as the extreme points were the ones of interest, and there was no central anchoring point as is usual in a likert scale. Rather a nominal scale was used.

\section{RESULTS}

\section{Demographics}

Out of a class of 26 students, 16 responded to the online survey (See Table 1, below). Most were in the 20-29 age-category, $67 \%$, while $27 \%$ were less than 20 years old. Only $6 \%$ were in the $30-39$ age-category. Most were male, $56 \%$. Fifty-six percent felt they had moderated experience with the course content material, while $38 \%$ felt they had minimum experience with it. Six percent had extensive experience. Most, 63\%, reported they had moderate experience with computers, $31 \%$ felt they had extensive experience. 


\begin{tabular}{|c|c|c|c|c|c|c|c|c|c|c|c|c|}
\hline \multicolumn{13}{|c|}{ "Table 1 - Demographic Distribution } \\
\hline & \multicolumn{4}{|c|}{ Age \% } & \multicolumn{2}{|c|}{ Gender \% } & \multicolumn{3}{|c|}{$\begin{array}{c}\text { Course Content } \\
\text { Experience \% }\end{array}$} & \multicolumn{3}{|c|}{$\begin{array}{c}\text { Computer } \\
\text { Experience \% }\end{array}$} \\
\hline $\mathbf{N}$ & $<20$ & $20-29$ & 30-39 & $39+$ & $\mathbf{M}$ & $\mathbf{F}$ & Min & Mod & Ext & Min & Mod & Ext \\
\hline 16 & 27 & 67 & 6 & 0 & 56 & 44 & 38 & 56 & 6 & 6 & 63 & 31 \\
\hline
\end{tabular}

\section{Perceptions}

Effective knowledge management presupposes effective thinking skills, team-building skills, as well as the resources needed to support them, whether on- or off-line. The results are therefore presented in this format (See Table 2, below).

There was more uniformity in the perceptions of the support the offline resources offered to the developing of thinking skills than for team-building skills. Most perceived a lot of support from all the offline resources for developing thinking skills, ranging from $50 \%$ to as high as $94 \%$ for the support that cases provided to developing research skills. Text was the only offline resource which was perceived as contributing only somewhat, 56\%, to creative idea generation. The results were more variable for the support of the team-building skills but not surprising. The text was perceived as offering only moderate support for developing communication skills, 38\%, and work coordination, $60 \%$, and not at all contributing to developing team cooperation, $44 \%$. As expected, given the nature of their content and the course design, the cases and activities and assignments of the course were perceived by most as offering a lot of support to the team-building skills. The exception was the support of the activities and assignments for team cooperation where most, $56 \%$, perceived some support. However, $44 \%$ did perceive a lot of support so this may be indicative of the extent to which teams had or did not have internal issues.

Moving to the technological supports, the online resources, there is once again more consistency in the perceptions with respect to support of the thinking skills than for the team-building skills, however, the perceptions are less enthusiastic. Most view the online resources as contributing only somewhat to the development of the thinking skills, except for the in-team discussion boards where most, 43\%, perceived a lot of support for developing critical thinking skills and most, 38\%, perceived Blackboard overall as contributing not at all to developing research skills.

The results were more variable for the contribution of online resources to developing team-building skills, but also more favorable. Most resources were viewed as offering a lot of support to the development of the teambuilding skills, with some exceptions. Material in Blackboard was perceived by $71 \%$ as providing only moderate support for developing communication skills, and by $64 \%$ as supporting work coordination and team cooperation. Forty-three percent also felt only moderate support from the public and in-team discussion boards for team cooperation. As these online forums were the major means by which students interacted, exchanged and debated ideas proposed by their team and other teams, this result is surprising. 


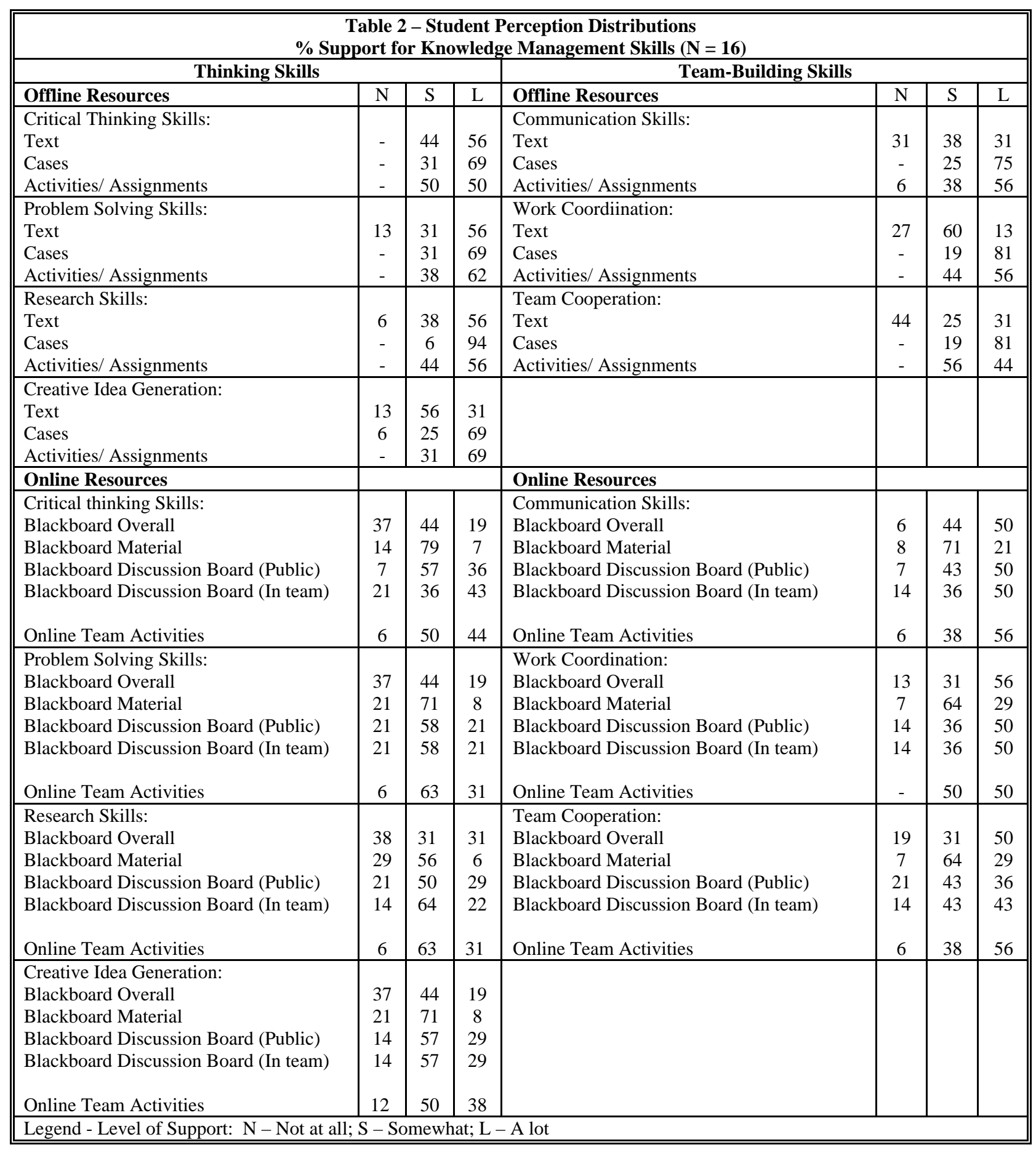




\section{CONCLUSION}

Generally, the results seem to indicate that more support of the thinking skills was provided by the offline resources than by the online resources, which was consistent with the prior study which focused on web-assisted course delivery (Thomas, 2005). Both the online and offline resources were perceived as providing a lot of support for the team-building skills, except for the text and the material in Blackboard, which was moderate.

The sample is small so drawing any far-reaching conclusions are not possible. The results, however, do indicate the need for further research and investigation into the relationship between on- and offline resources and their contribution to developing knowledge management skills - thinking and team-building skills. These skills are vitally important in today's organizations, especially given the graphical dispersion of these organizations and the tendency for work to be conducted more and more in virtual environments.

The fact that in an entirely online, team-based course, students still perceived more support from offline resources than online resources is interesting. Is this simply a matter of conditioning, requiring learning a new way of doing things and therefore will change over time and experience? Is it a function of the inadequacy of the online resources, content or design? Or is it a function of the type of learning or task? These are questions that need to be answered.

By framing research within the context of the models presented in this paper, comparison across studies will be facilitated. Studies exploring how placement within the various spectra, whether in isolation or combination, impact on learning and the learning process present other fruitful avenues for research. Both of these streams of research and their contribution to knowledge management in organizations promise to provide fodder for research far into the future.

\section{REFERENCES}

1. Alavi, M. \& D.E. Leidner (2001) Review: Knowledge management and knowledge management systems: Conceptual foundations and research issues, MIS Quarterly, 25(1), pp. 107-136.

2. Bayraktaroglu, S and R O. Kutanis (2003) The Changing Trends for the Training Technologies within the (sic) Europe: The Case of British Companies, in Global Business and Technology Association, p. 178-185.

3. Coppola, J.F., \& B.A. Thomas (2000) Beyond 'chalk and talk': A model for e-classroom design, T.H.E. (Technological Horizons in Education) Journal, 27 (6).

4. Davis, F. D. (1989) Perceived usefulness, perceived ease of use, and user acceptance in information technology, MIS Quarterly, 13(3), pp. 319-340.

5. $\quad$ Ein-Dor, P. (2006) Taxonomies of Knowledge, in Encyclopedia of Knowledge Management, David G. Schwartz, Ed., Idea Group Publishing: Hershey, PA, pp. 848-854.

6. Gabberty, J.W. and Thomas, J.D.E. (2007) Driving Creativity: Extending Knowledge Management into the Multinational Corporation, Interdisciplinary Journal of Information, Knowledge, and Management, 2, pp. 115.

7. Heavin, C. \& K. Neville (2006) Mentoring Knowledge Workers, in Encyclopedia of Knowledge Management, David G. Schwartz, Ed., Idea Group Publishing: Hershey, PA, pp. 621-626.

8. Hult, G.T.M. (2003) An Integration of Thoughts on Knowledge Management, Decision Sciences, 34(2), pp. 189-195.

9. King, W.R. (2006) Knowledge Transfer, in Encyclopedia of Knowledge Management, David G. Schwartz, Ed., Idea Group Publishing: Hershey, PA, pp. 538-543.

10. Liebowitz, J. (2002) Knowledge Management in a Large Government Organization, in Proceedings of the IASTED International Conference on Information and Knowledge Sharing, November 18-20, St. Thomas, US Virgin Islands, 2002 pp. 51-53.

11. Nonaka, I. (1991) The Knowledge-Creating Company, Harvard Business Review, November- December 1991, pp. 21-46. 
12. Reeves, T.C. \& P.M. Reeves (1997) Effective dimensions of interactive learning on the World Wide Web, in B.H. Khan (Ed.), Web-based instruction, Englewood Cliffs, NJ: Educational Technology Publications, Inc., pp. 79-96.

13. Sambamurthy, V. and M. Subramani (2005) Special issue on information technologies and knowledge management, MIS Quarterly, 29(1), pp. 1-7.

14. Speter J.L. and J.L, Speter (2003) Does Employee Learning Lead to Success for the Company?, in Global Business and Technology Association, pp. 1199-1206.

15. Thomas, J.D.E. (2005) Support of Students' Acquisition of Knowledge Management Skills in Academia, in Proceedings of $5^{\text {th }}$ Annual Hawaii International Conference on Business, Honolulu, Hawaii, pp. 3016-3019.

16. Thomas, J.D.E. and London, L. (1997) Using the Reeves and Harmon Model to Evaluate Interactive Multimedia, in Proceedings of the 1997 ED-MEDIA/ED-Telecom 97 World Conferences on Educational Multimedia and Hypermedia and on Educational Telecommunications, Alberta, Canada, Jun 14-19.

17. Torrellas, G.A.S. (2002) A Framework for Learning Model Innovation using Knowledge Engineering, in Proceedings of the IASTED International Conference on Information and Knowledge Sharing, November 18-20, St. Thomas, US Virgin Islands, 2002, pp. 32-38.

\section{NOTES}

